\title{
Rancang Bangun Alternator Mobil Menggunakan Magnet Permanen
}

\author{
Andareas Pangkung ${ }^{*}$, A. M. Shiddiq Yunus², Mustari Nur Mulyadi ${ }^{3}$ dan Padidi Alfrianto Illa $^{4}$ \\ 1,2 Jurusan Teknik Mesin, Politeknik Negeri Ujung Pandang, Makassar 90245, Indonesia \\ ${ }^{3,4}$ Alumni Jurusan Teknik Mesin, Politeknik Negeri Ujung Pandang, Makassar 90245, Indonesia \\ *andareaspangkung@gmail.com
}

\begin{abstract}
The electric power system is one of the sources of electricity found in the vehicle which functions as a starter and electric component of the vehicle. The battery (battery) is a source of electricity to meet the electrical system in the car, but the battery is only a place to store electric charge. Therefore, there is an alternator as a power generator to charge the battery. The alternator on a car uses artificial magnets in its rotor which still require excitation. Therefore, it encourages the author to analyze the comparison of alternators using permanent magnets and artificial magnets. The problem that arises is how to compare rotation, voltage, and output power on the alternator using permanent magnets and artificial magnets. The purpose of this study was to determine the ratio of the output power generated by the alternator using permanent magnets and artificial magnets. Research and Development Methods are research methods used to produce certain products, and test the effectiveness of these products. Based on the results of the tests carried out, it was found that at the same rotation an alternator with a permanent magnet generates a greater output power than the artificial magnet. However, at the same rotation the motor requires more input power to rotate the alternator when using permanent magnets. When the alternator output voltage is the same, the rotation of the alternator using the permanent magnet is lower.
\end{abstract}

Keywords: Alternator, Permanent magnet, Artificial magnet.

\begin{abstract}
Abstrak: Sistem tenaga listrik merupakan salah satu sumber listrik yang terdapat pada kendaraan berfungsi untuk stater dan kompenan listrik kendaraan. Baterai (aki) menjadi sumber listrik untuk memenuhi sistem kelistrikan pada mobil, namun baterai hanya sebagai tempat penyimpanan muatan listrik. Maka dari itu, terdapat alternator sebagai pembangkit listrik untuk mengisi baterai. Alternator pada mobil menggunakan magnet buatan pada rotornya yang masih membutuhkan eksitasi. Oleh karena itu, mendorong penulis untuk menganalisis perbandingkan alternator menggunakan magnet permanen dan magnet buatan. Permasalahan yang timbul adalah bagaimana perbandingan putaran, tegangan, dan daya output pada alternator menggunakan magnet permanen dan magnet buatan. Tujuan penelitian ini ialah untuk mengetahui perbandingan daya output terbangkit pada alternator menggunakan magnet permanen dan magnet buatan. Metode Penelitian dan Pengembangan adalah metode penelitian yang digunakan untuk menghasilkan produk tertentu, dan menguji keefektifan produk tersebut. Berdasarkan hasil pengujian yang dilakukan didapatkan, pada putaran yang sama alternator dengan magnet permanen membangkitkan daya output lebih besar daripada magnet buatan. Akan tetapi, pada putaran yang sama motor membutuhkan daya input yang lebih besar untuk memutar alternator saat menggunakan magnet permanen. Ketika tegangan output alternator sama, putaran pada alternator menggunakan magnet permanen lebih rendah.
\end{abstract}

Kata kunci : Alternator, Magnet permanen, Magnet buatan.

\section{PENDAHULUAN}

Sistem tenaga listrik merupakan salah satu sumber listrik yang terdapat pada kendaraan. Setiap kendaraan selalu membutuhkan tenaga listrik seperti saat kendaraan distater dan saat menggunakan peralatan bantu lainnya pada mobil yang menggunakan energi listrik tidak dapat difungsikan. Oleh karena itu di dalam mobil dibutuhkan suatu sistem yang dapat memenuhi fungsi dari sistem kelistrikan pada mobil yaitu komponen berupa battery atau aki, sehingga dapat meyuplai arus pada komponenkomponen yang membutuhkan listrik. Dalam hal ini karena battery hanya merupakan tempat penyimpanan energi listrik [1]. Untuk itu, dalam sistem pengisian dilengkapi dengan suatu alternator 
yang berfungsi untuk menghasilkan sumber listrik yang digerakkan oleh $V$ - belt. Jika penggunaan tenaga listrik dilakukan secara terus menerus tanpa dilakukan pengisian kembali, dapat dipastikan kemampuan battery akan menurun atau tegangan menjadi lemah. Oleh karena itu, sistem pengisian sangat dibutuhkan pada setiap kendaraan, dengan maksud mengembalikan kapasitas battery pada kondisi full charge disamping harus menggantikan fungsi battery selama mesin hidup [2].

Sistem pengisian mempunyai beberapa tipe, yaitu sistem pengisian tipe titik kontak atau yang biasa disebut dengan tipe mekanik dan sistem pengisian dengan menggunakan IC regulator. Kedua tipe tersebut mempunyai prinsip dasar yang sama, akan tetapi mempunyai beberapa perbedaan dalam segi komponen dan rangkaian kelistrikan. Perbedaan pokok bahwa regulator IC pemutusan arus dilakukan oleh IC, sedangkan pada tipe titik kontak atau mekanik dilakukan oleh relay. Berikut adalah kelebihan dari sistem pengisian dengan menggunakan IC regulator [3]

Alternator pada kendaraan umumnya menggunakan magnet buatan, dimana membutuhkan sumber listrik sebagai pemberian arus listrik untuk membuat kutub magnet pada alternator (eksitasi). Ketika battery kendaraan habis, maka dibutuhkan suplai dari luar sebagai eksitasi pada alternator. Saat alternator tidak mendapatkan suplai dari luar, sistem pengisian tidak akan berfungsi. Hal ini akan membuat sistem kelistrikan pada kendaraan tidak dapat digunakan. Oleh karena itu, dalam hal ini mendorong penulis untuk menganalisis perbandingan altenator menggunakan magnet buatan dan magnet permanen [5]-[7].

Pada alternator mobil daya terbangkit berubah-ubah, hal ini disebabkan putaran pada mesin tidak konstan. Oleh karena itu daya yang dibangkitkan itu harus dapat diredam, maka dari itu alternator mempunyai konstruksi yang sederhana, dan selain itu terdapat beberapa kelebihan bila dibandingkan dengan dynamo. Kelebihan pada alternator ialah tidak terdapat bunga api antara sikat- sikat dan slip ring, disebabkan tidak terdapat komutator yang dapat menyebabkan sikat menjadi aus. Rotornya lebih ringan dan tahan terhadap putaran tinggi, dan silicon diode (rectifer) mempunyai sifat pengarahan arus, serta dapat mencegah kembalinya arus dari baterai ke alternator. Untuk mencegah kesalahpahaman, sebenarnya generator arus bolak - balik menghasilkan arus searah seperti dynamo arus searah dengan mempergunakan beberapa dioda. Disini alternator dapat disamakan dengan generator arus bolak-balik. Pada saat magnet digerakan dekat kumparan akan timbul gaya electromagnet pada kumparan. Arah tegangan yang dibangkitkan pada saat magnet bergerak mendekat atau menjauhi kumparan juga berlawanan. Besarnya tegangan yang akan dibangkitkan akan meningkat sesuai dengan meningkatnya gaya magnet dan kecepatan gerak magnet [8], [9].

Gaya gerak listrik yang dibangkitkan dalam kumparan akan bertambah dengan besar bila perubahan medan magnetnya berjalan dengan cepat. Dengan kata lain, bertambah banyak dan cepatnya flux magnet yang mengalir melalui kumparan, maka gaya gerak listrik yang dibangkitkan juga bertambah besar [10].

Hubungan tersebut dapat dinyatakan dengan :

(e) $=-\mathrm{N}\left\{\frac{\Delta \Phi}{\Delta t}\right\}$

Dengan :

$\mathrm{N} \quad$ : banyak lilitan dari kumparan

$\Delta \Phi \quad$ : perubahan flukx magnit dalam satuan webber (Wb)

$\Delta t \quad$ : perubahan waktu dalam satuan detik (dt)

Dan daya :

$\mathrm{P}=\mathrm{V} \times \mathrm{I}$

Dimana :

$\begin{array}{ll}\mathrm{P} & : \text { Daya (watt) } \\ \mathrm{V} & : \text { Tegangan (volt) } \\ \mathrm{I} & : \text { Arus (ampere) }\end{array}$ 
175 Andareas Pangkung, A. M. Shiddiq Yunus, Mustari Nur Mulyadi, Padidi Alfrianto Illa. Rancang Bangun Alternator Mobil Menggunakan Magnet Permanen

\section{METODE PENELITIAN}

Pada penelitian ini beberapa tahapan penelitian meliputi rancangan rangkaian listrik system seperti terlihat pada gambar 1-3.

a) Rangkaian motor penggerak

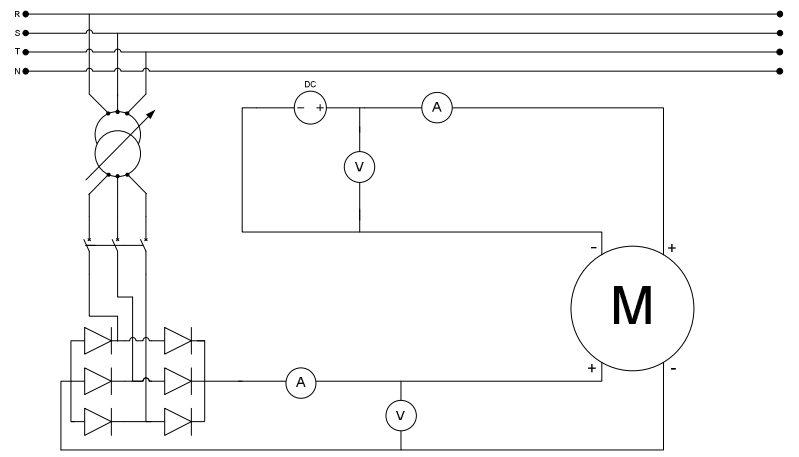

Gambar 1. Diagram rangkaian motor penggerak

b) Rangkaian alternator tanpa beban

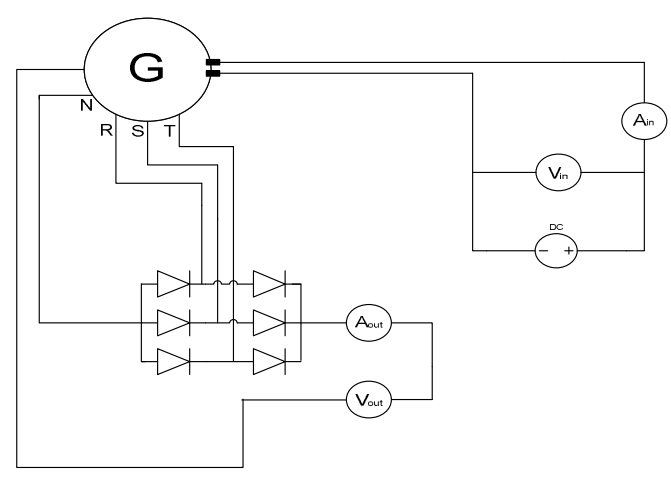

Gambar 2. Diagram rangkaian alternator tanpa beban

c) Rangkaian alternator berbeban

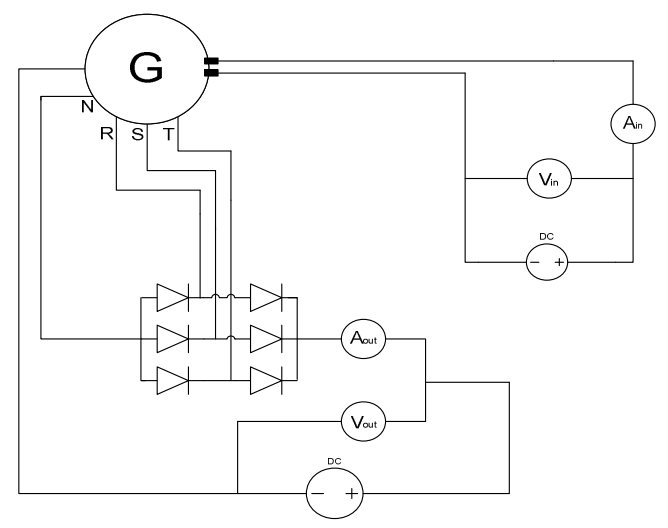

Gambar 3. Diagram rangkaian alternator berbeban

Dalam penelitian ini dapat dijelaskan dengan oleh diagram alir penelitian. Diagram alir Analisis Alternator: 


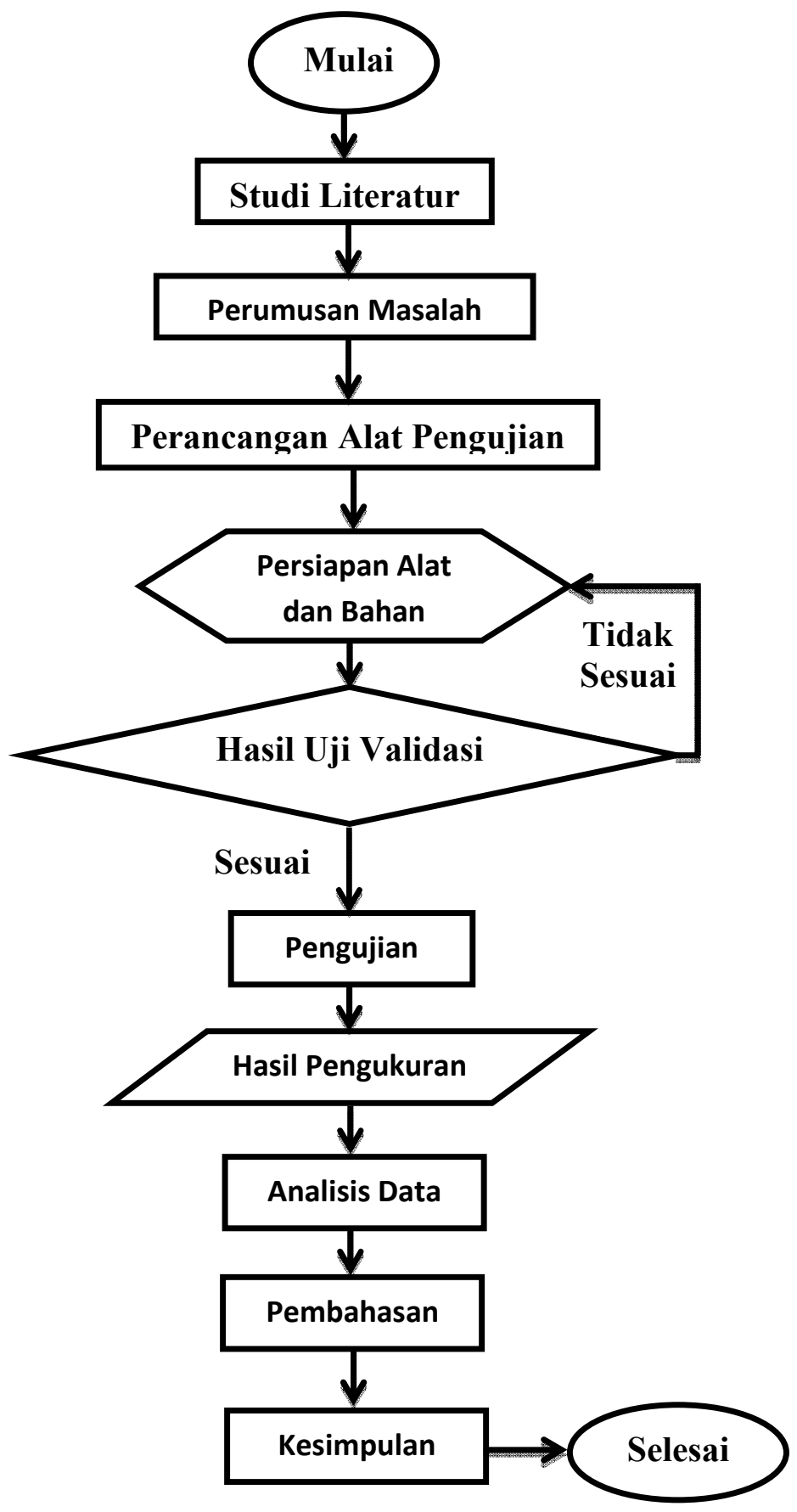

Gambar 4. Diagram alir penelitian

\section{HASIL DAN PEMBAHASAN}

Pada gambar 5 digambarkan bahwa semakin tinggi putaran maka semakin tinggi daya yang terbangkitkan baik saat menggunakan magnet permanen maupun magnet buatan. Akan tetapi, daya yang terbangkitkan magnet permanen lebih tinggi dibandingkan magnet buatan diputaran yang sama. Dimana pada putaran akhir 2500 rpm magnet permanen menghasilkan daya sebesar 504 watt, 
177 Andareas Pangkung, A. M. Shiddiq Yunus, Mustari Nur Mulyadi, Padidi Alfrianto Illa. Rancang Bangun Alternator Mobil Menggunakan Magnet Permanen

sedangkan pada magnet buatan 306 watt.

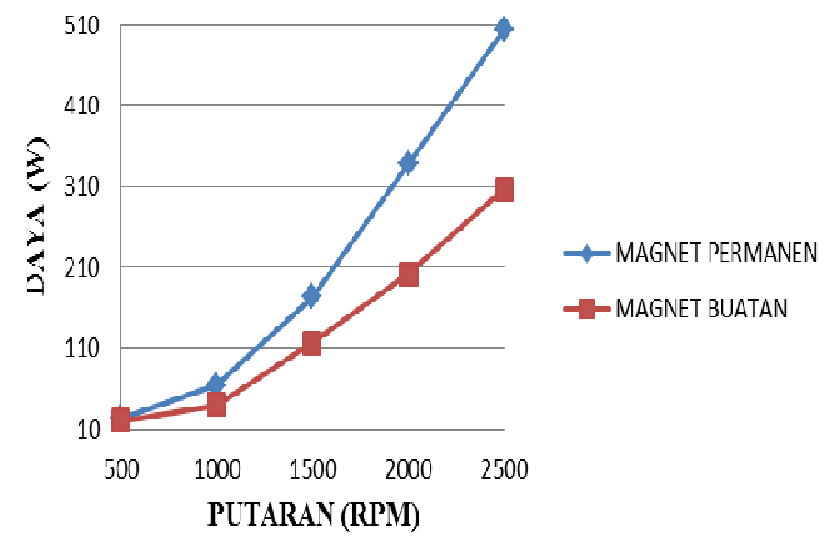

Gambar 5. Grafik hubungan daya output dan putaran pada alternator berbeban.

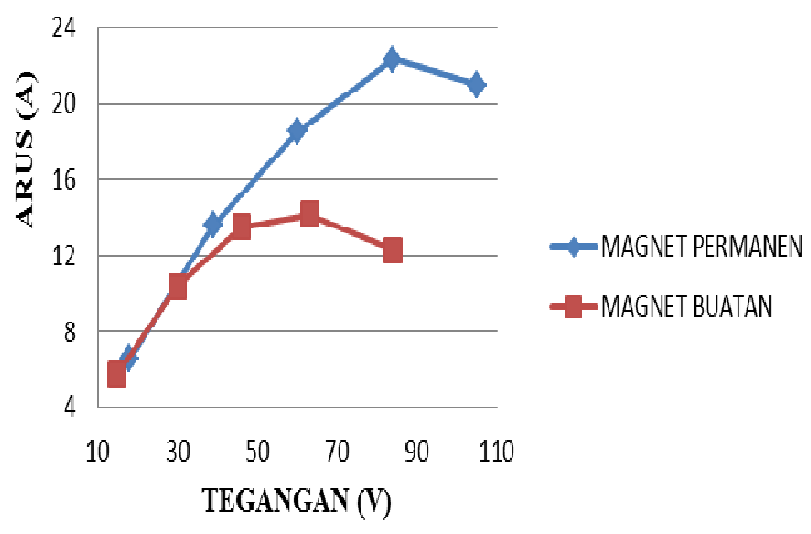

Gambar 6. Grafik hubungan tegangan dan arus input pada motor saat alternator berbeban.

Pada gambar 6 terlihat bahwa tegangan dan arus yang dibutuhkan motor untuk memutur alternator menggunakan magnet permanen lebih besar dari alternator menggunakan magnet buatan. Dimana, saat menggunakan magnet permanen data terakhir pada putaran $2500 \mathrm{rpm}$ membutuhkan tegangan 105 volt dan arus 21 ampere. Sedangkan untuk magnet buatan, membutuhkan tegangan 84 volt dan arus 12.3 ampere.

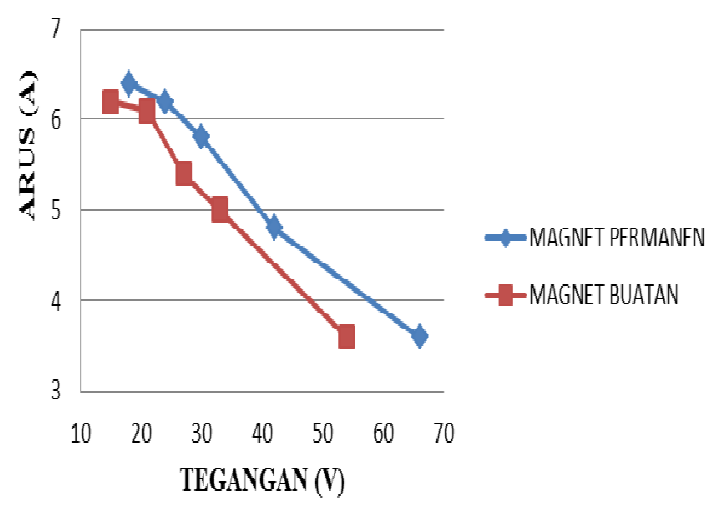


Gambar 7. Grafik hubungan tegangan dan arus input pada motor saat alternator tanpa beban.

Dari gambar 7 menjelaskan bahwa semakin tinggi tegangan input pada motor yang digunakan untuk memutar alternator menggunakan magnet permanen dan magnet buatan, maka semakin rendah arus input. Tegangan dan arus input motor pada alternator dengan magnet permanen lebih tinggi dari magnet buatan, hal ini disebabkan karena medan magnet yang terjadi pada magnet permanen lebih besar dari magnet buatan. Dapat dilihat pada data terakhir pengujian pada magnet permanen, motor membutuhkan tegangan input 66 volt dan arus input 3.6 ampere. Sedangkan pada magnet buatan tegangan input 54 volt dan arus input 3.6 ampere.

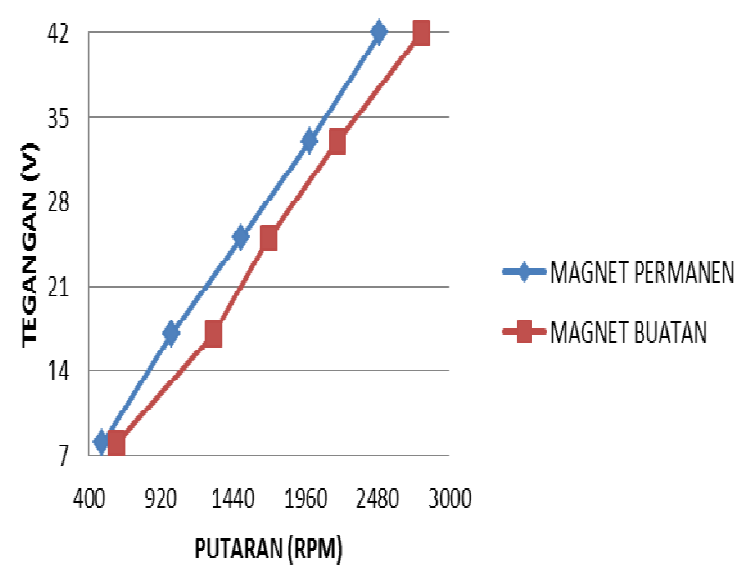

Gambar 8. Grafik hubungan tegangan output dan putaran pada alternator tanpa beban.

Gambar 8 menjelaskan bahwa semakin tinggi putaran alternator maka semakin tinggi tegangan dibangkitkan. Pada grafik terlihat, saat pengujian menggunakan magnet permanen putaran lebih rendah dari magnet buatan dengan tegangan output dibangkitkan alternator sama. Dapat dilihat pada data terakhir tegangan output $42 \mathrm{~V}$ dengan magnet permanen membutuhkan putaran $2500 \mathrm{rpm}$, sedangkan untuk magnet buatan membutuhkan putaran 2800 rpm.

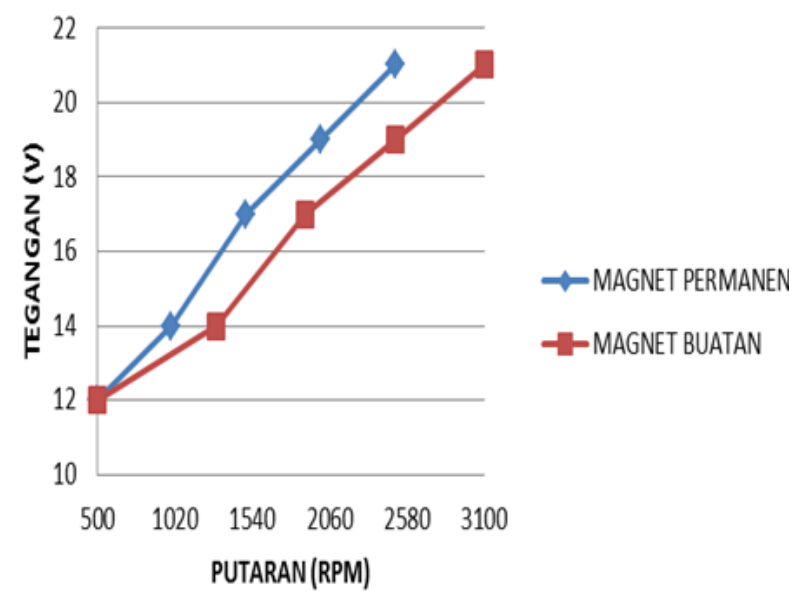


Gambar 9. Grafik hubungan tegangan output dan putaran pada alternator berbeban.

Dari gambar 9 terlihat bahwa semakin tinggi putaran alternator maka semakin tinggi tegangan dibangkitkan. Pada grafik terlihat, saat pengujian menggunakan magnet permanen putaran lebih rendah dari magnet buatan dengan tegangan output dibangkitkan alternator sama. Dapat dilihat pada data terakhir tegangan output $21 \mathrm{~V}$ dengan magnet permanen membutuhkan putaran $2500 \mathrm{rpm}$, sedangkan untuk magnet buatan membutuhkan putaran $3100 \mathrm{rpm}$.

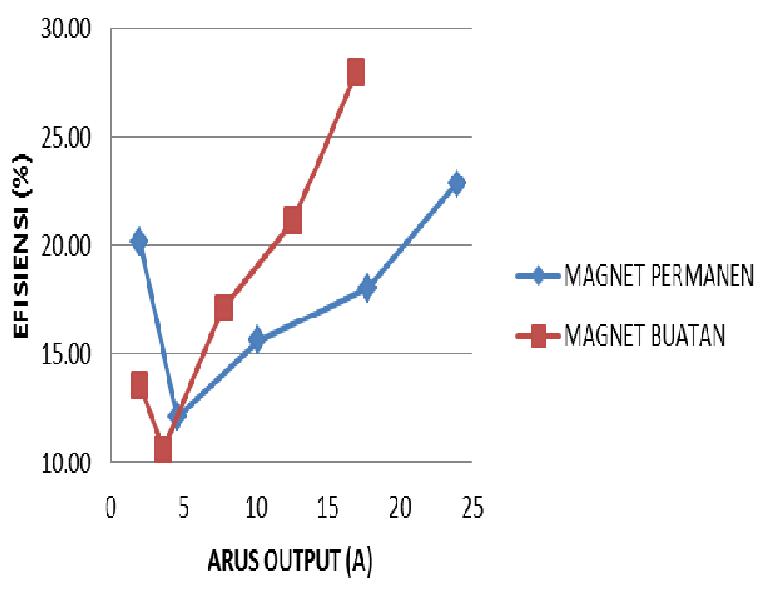

Gambar 10. Grafik hubungan efisiensi dengan arus output pada alternator berbeban.

Grafik diatas menjelaskan bahwa semakin tinggi arus output alternator maka semakin tinggi pula efisiensi, tapi untuk data pertama pada magnet permanen maupun magnet buatan memiliki efisiensi cukup besar sehingga efisiensi menurut pada data kedua. Dapat lihat pada data pertama pengujian mnggunakan magnet buatan efisiensi 13,61 \% dan untuk magnet permanen efisiensi 20,20\%. Pada data kedua menurun saat menggunakan magnet buatan efisiensi $10,65 \%$ dan untuk magnet permanen $12,14 \%$. Kemudian, data selanjutnya efisiensi saat menggunakan magnet buatan dan magnet permanen akan terus meningkat hingga data terakhir.

Berdasarkan hasil pengujian daya output alternator menggunakan magnet permanen lebih besar, hal ini dikarenakan tegangan dan arus output besar. Alternator dengan magnet buatan menggunakan IC regulator sebagai pengontrol excitasi yang berpengaruh terhadap output dari alternator. Saat menggunakan magnet permanen tegangan output yang besar belum dapat dikontrol sesuai kebutuhan komponen listrik pada mobil, hal tersebut dapat membuat komponen pada mobil rusak.

Panas yang diakibatkan arus output yang besar dan gesekan pada bantalan alternator pada pengujian dapat menyebabkan magnet permanen kehilangan medan magnet. Salah satu kelemahan dari magnet permanen ialah ketika mendapat panas yang berlebih atau dibakar, membuat sifat kemagnetan pada magnet permanen akan hilang.

\section{KESIMPULAN}

Setelah melakukan pengujian alternator menggunakan magnet permanen dan magnet buatan, didapatkan beberapa perbandingan dengan parameter yang berbeda. Adapun kesimpulannya sebagai berikut:

1. Pada putaran yang sama, alternator dengan magnet permanen membangkitkan daya output lebih besar tetapi motor penggerak membutuhkan daya input yang lebih besar.

2. Alternator menggunakan magnet permanen tidak dapat digunakan pada mobil disebabkan belum terdapat pengontrol tegangan output dan panas yang terjadi dapat menghilangkan sifat kemagnetan. 


\section{DAFTAR PUSTAKA}

[1] Anggraini Rivalia,Dkk.2013. Listrik Magnet. Jember

[2] Chasbulla Wahib, Dkk. 2018. Magnet dan Medan Magnet Tidak Diterbitkan

[3] Honda. 2002. Technical Information Guide. Jakarta: Honda Motor Co., Ltc.

[4] Juhardi, Eng Dipel.2013. Generator Semester 3. Tidak Diterbitkan

[5] Khusnussairi, M. 2013.Pengujian Sistem Pengisian Pada Mesin Honda Jazz Tipe L13A.Semarang.

[6] Nippondenso. 1980. Alternator. Semarang.

[7] Noprizal Leo,Dkk. 2016. Perancangan Prototype Generator Magnet Permanen 1 Fasa Jenis Fluks Aksial pada Putaran Rendah.Banda Aceh

[8] Setiono, Puji. 2006. Pemanfaatan Alternator Mobil Sebagai Pembangkit Listrik Tenaga Angin. Semarang.

[9] Wigraha, Arya dkk. 2017. Pengembangan Alternator Ganesha Electric Vehicles 1.0 Generasi I

[10] Yayat Supriatna. Sumarsono. 1998. Listrik Otomotif 1. Bandung : Angkasa. 